\title{
Activated protein $C$ in septic shock: a propensity-matched analysis
}

\author{
Farid Sadaka*, Jacklyn O'Brien, Matthew Migneron, Julie Stortz, Alexander Vanston, Robert W Taylor
}

\begin{abstract}
Introduction: The use of human recombinant activated protein C (rhAPC) for the treatment of severe sepsis remains controversial despite multiple reported trials. The efficacy of rhAPC remains a matter of dispute. We hypothesized that patients with septic shock who were treated with rhAPC had an improved in-hospital mortality compared to patients with septic shock with similar acuity who did not receive rhAPC.

Methods: This retrospective cohort study was completed at a large university-affiliated hospital. All patients with septic shock admitted to a 50-bed ICU between July 2003 and February 2009 were included. Patients were treated according to sepsis management guidelines.

Results: A total of 563 septic shock patients were included (110 received rhAPC and 453 did not). Treated and untreated groups were matched in patient characteristics, comorbidities, and physiologic variables in a 1:1 propensity-matched analysis (108 received rhAPC, 108 did not). Mean Acute Physiology And Chronic Health Evaluation II (APACHE II) scores were 24.5 for the matched treated and 23.9 for the matched untreated group ( $P=$ 0.54). Receipt of rhAPC was associated with reduced in-hospital mortality ( $35.2 \%$ vs. $53.8 \%, P=0.005)$, similar mean days on vasopressors ( 2 vs. $2, P=0.90$ ), similar mean days on mechanical ventilation ( 9 vs. $8.7, P=0.80$ ), similar mean length of ICU stay in days (11.0 vs. $11.3, P=0.90)$, and similar mean length of hospital stay in days (19.5 vs $27, P=0.11$ ). No patients in either group had intracranial bleeding; differences in gastrointestinal bleeding and transfusion requirements were not statistically significant.

Conclusions: Patients in our institution with septic shock who were treated with rhAPC had a reduced in-hospital mortality compared with patients with septic shock with similar acuity who were not treated with rhAPC. In addition, time on mechanical ventilation, time on vasopressors, lengths of stay and bleeding complications did not differ between the groups.
\end{abstract}

\section{Introduction}

In the United States alone, approximately 750,000 cases of sepsis occur each year, of which at least 225,000 are fatal. One study evaluating the epidemiology of sepsis between 1979 and 2000 showed an 8.7\% increase in the annual incidence of sepsis. The cost of management of a septic patient is approximately $\$ 50,000$ amounting to annual costs estimated at $\$ 17$ billion. Sepsis is the second leading cause of death in noncoronary Intensive Care Units (ICUs), and the $10^{\text {th }}$ leading cause of death overall. Organ failure occurs in $33.6 \%$ of patients with sepsis. Severe sepsis carries an estimated 30 to $50 \%$ mortality. Seventy percent of patients with three or more organ

\footnotetext{
* Correspondence: farid.sadaka@mercy.net

St. John's Mercy Medical Center/St Louis University, $621 \mathrm{~S}$ New Ballas Rd., Suite 4006B, St. Louis, MO 63141, USA
}

failures die. Those who survive severe sepsis have a lower quality of life compared to the age- and gender-adjusted general population, as much as 1.5 years later [1-7].

Sepsis is a complex syndrome that remains incompletely understood. It has proven very difficult to tailor new therapies for severe sepsis. One such potential therapy is Recombinant Human Activated Protein C (rhAPC). The use of rhAPC for the treatment of severe sepsis remains controversial despite multiple reported trials [8-13]. The Prospective Recombinant Human Activated Protein C Worldwide Evaluation in Severe Sepsis (PROWESS) trial reported a $6 \%$ absolute reduction in mortality together with a $1.5 \%$ absolute increase in the risk of serious bleeding in patients receiving rhAPC compared to those receiving placebo [8]. In a subgroup analysis of the PROWESS trial, patients with higher risk of death had a larger
C Biomed Central

(c) 2011 Sadaka et al.; licensee BioMed Central Ltd. This is an open access article distributed under the terms of the Creative Commons Attribution License (http://creativecommons.org/licenses/by/2.0), which permits unrestricted use, distribution, and reproduction in any medium, provided the original work is properly cited. 
drop in hospital mortality compared to patients with a lower risk of death. In patients with Acute Physiologic and Chronic Health Evaluation II (APACHE II) score $>25$, hospital mortality dropped from $47.9 \%$ to $36.7 \%$ ( $P$ $=0.002$ ) with rhAPC treatment [9]. In patients with three, four, or five organ failures, hospital mortality dropped from $37.0 \%$ to $30.5 \%, 50.1 \%$ to $44.9 \%$, and $63.3 \%$ to $32.5 \%$, respectively [9]. In contrast, a subsequent trial suggested that patients with lower mortality risk did not benefit [10]. Widespread clinical use of rhAPC has likely also been limited by its cost estimated at $\$ 7,500$ to $\$ 9,000$ per course of therapy [14-16].

Two large multicenter trials evaluating the effect of rhAPC in septic shock patients are currently underway $[17,18]$. We examined the association between rhAPC and outcomes in septic shock patients in our institution, with the hypothesis that patients with septic shock who were treated with rhAPC had an improved in-hospital mortality compared to patients with septic shock with similar acuity who did not receive rhAPC.

\section{Materials and methods Subjects}

This investigation is a retrospective cohort study of patients admitted to a large university affiliated hospital with 56 medical-surgical intensive care unit (ICU) beds, between July 2003 and February 2009. Data were obtained from a large, multiinstitutional, critical care patient data set (Project Impact Critical Care Data System). Project IMPACT (PI) is a comprehensive database system developed to measure and describe the care of ICU patients. Developed by a multidisciplinary group of critical care expert members of the Society of Critical Care Medicine, this system allows practitioners to quantify practice patterns and patient outcomes and compare them with those of similar ICUs. Personnel at $>100$ ICUs at multiple participating hospitals enter information for $>100$ defined patient data elements into the PI software. Data elements include patient demographics, treatment, outcomes, complications, and resource utilization. On a quarterly basis, data from all hospitals are merged into the PI central database. Reports are then generated that include both summary and individual hospital data. Specifically, data on age, height, ICU admission weight, gender, comorbidities, organ failures, and ICU and hospital LOS were collected. PI data at our institution were collected by experienced registered ICU nurses (more than 16 years experience). Additional data elements were collected from the patients' electronic medical records.

Patients were included if they were 18 years of age or older, had a principal diagnosis of sepsis as defined by the 1992 SCCM/ACCP consensus conference definition
[19], admitted to the ICU, and if they developed systolic blood pressure less than $90 \mathrm{mmHg}$, not responding to appropriate fluid resuscitation, and requiring vasopressors to maintain mean arterial pressure greater than or equal to $65 \mathrm{mmHG}$ [19]. All sepsis patients in our institution are managed based on current sepsis management guidelines [20,21].

Baseline characteristics including demographic information and information about preexisting conditions, organ function/failure, infection, and pertinent medications were collected. APACHE II scores and sequential organ failure assessment (SOFA) scores were calculated. In all patients that received rhAPC, the infusion was started within 24 hours of development of septic shock. Presence or development of acute organ failures was documented. Organ failure definitions are shown in Table 1. The conduction of this study was approved by the Institutional Review Board at St. John's Mercy Medical Center (Approval \#10-084). The board waived the need for informed consent.

\section{Outcomes}

The primary outcome measure was in-hospital mortality. We also recorded complications, including the occurrence of intracranial hemorrhage, gastrointestinal hemorrhage, major transfusions, and minor transfusions. Major transfusion was defined as the administration of six or more units of red blood cells within two consecutive days or four or more units in any single day. Minor transfusion was defined as the administration of two or three units of packed red blood cells in a single day. ICU-specific outcomes included length of stay, number of days spent on vasopressors and number of days on mechanical ventilation. We also assessed hospital length of stay.

\section{Analysis}

Summary statistics were calculated for categorical and numeric data. For categorical data, frequencies and proportions (as percentages) are reported. For numeric data, means, standard deviations, medians and lower and upper quartiles are reported. Propensity for treatment with rhAPC was estimated by fitting a nonparsimonious logistic regression model containing 22 independent variables (Table 2). These variables were selected because they conceivably could bear on the choice to administer rhAPC. The c statistic was 0.75 . The Hosmer-Lemeshow chi-square was $12.55(\mathrm{df}=8)$, with a non-significant $P$-value of 0.13 , which indicates the model is well-calibrated. Once the propensity scores were obtained, we used the recently described "fine balance" method of Rosenbaum, Ross, and Silber to produce 1:1 matched subjects [22]. Out of an overall number of 563 cases, we obtained 108 individuals treated 


\section{Table 1 Definitions of organ failures}

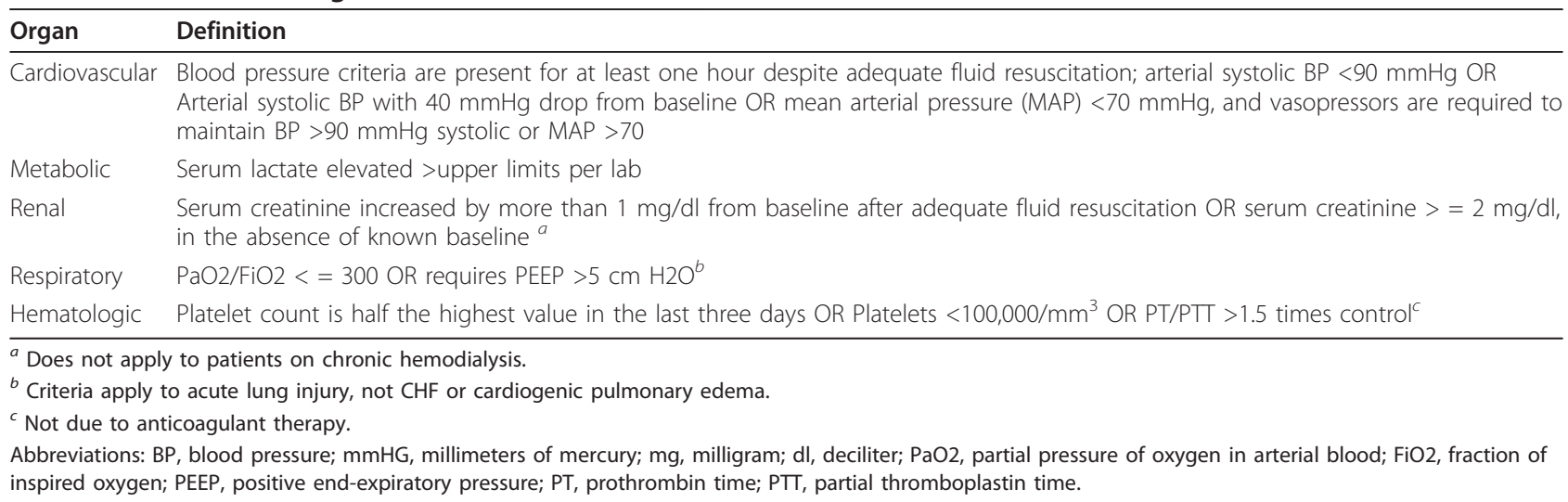

with rhAPC matched to 108 control individuals not treated with rhAPC.

Table 2 shows the characteristics of the treated and untreated matched subjects. No statistically significant differences were found, indicating that the matching process succeeded in identifying comparable pairs of individuals. All statistical tests took into account the paired nature of the data. There may be some differences between the overall cohort and the matched groups, but propensity matching has proved to be the best method for dealing with those differences. Table 3 shows the outcomes by treatment. All statistical tests took pairing into account, except for comparisons of lengths of stay and days on ventilator and vasopressors. These four comparisons were limited to survivors, which caused pairing to be broken.

\section{Results}

A total of 563 septic shock patients were included (110 received rhAPC and $453 \mathrm{did}$ not). Treated and untreated groups were matched in patient characteristics, comorbidities, physiologic variables, organ failures, and APACHE II scores (Table 2). Mean APACHE II scores were 24.5 for the matched treated and 23.9 for the matched untreated group $(P=0.54)$. In a $1: 1$ propensity-matched analysis, receipt of rhAPC was associated with reduced in-hospital mortality $(35.2 \%$ vs. $53.8 \%, P=$ $0.005)$, similar mean days on vasopressors ( 2 vs. $2, P=$ 0.90 ), similar mean days on mechanical ventilation ( 9 vs. 8.7, $P=0.80$ ), similar mean length of ICU stay in days (11.0 vs. $11.3, P=0.9)$, and similar mean length of hospital stay in days (19.5 vs $27, P=0.11)$. No patients in either group had intracranial bleeding. Differences in major transfusions $(3.7 \%$ vs $9.3 \%, P=0.09)$, minor transfusions ( $35.2 \%$ vs $41.7 \%, P=0.27)$, any transfusion (minor and/or major, $38 \%$ vs $46.3 \%, P=0.16$ ) and gastrointestinal bleeding $(2.8 \%$ vs $0 \%, P=1.00)$ were not statistically significant (Table 3).

\section{Discussion}

In this cohort propensity-matched analysis study, we found that patients with septic shock who were treated with rhAPC had a reduced in-hospital mortality compared with patients with septic shock with similar acuity who were not treated with rhAPC, with a relative risk reduction of $34.6 \%$, and absolute risk reduction of $18.6 \%$. This translates into a number needed to treat (NNT) to prevent a death of 5.4. We also found that the rate of bleeding in our cohort was similar to other published studies. In the major clinical trials, over the 28-day study period, serious bleeding events were observed in 3.5 to $6.5 \%$ of patients receiving rhAPC as compared with 2.0 to $5.0 \%$ of patients receiving the placebo [23]. Rates of intracranial hemorrhage were 0 to $1.5 \%$ with rhAPC as compared with 0 to $0.7 \%$ with the placebo.

The first large randomized trial studied a dose of $24 \mu \mathrm{g}$ per kilogram of body weight per hour in the phase 3 PROWESS study [8]. This placebo-controlled, randomized, double-blind, multicenter trial included 1,690 patients. Treatment with rhAPC within 24 hours after diagnosis was associated with a mortality rate of $24.7 \%$ at 28 days versus $30.8 \%$ with placebo $(P=0.005)$. The overall incidence of at least one bleeding event was $24.9 \%$ in the treatment group and $17.7 \%$ in the placebo group $(P=0.001)$ [24]. The incidence of serious bleeding in the PROWESS study was also higher in the rhAPC group than in the placebo group (3.5\% vs. $2.0 \%$, $P=0.06)$. In subgroup analyses, most of the benefit of rhAPC treatment was seen in patients at increased risk for death, including those with APACHE II scores of 25 or greater. A follow-up study, the Administration of Drotrecogin Alfa (Activated) in Early Stage Severe Sepsis (ADDRESS) trial, evaluated the role of rhAPC in patients with severe sepsis, associated with either singleorgan failure or an APACHE II score below 25 [10]. The study was stopped, after enrolling 2,640 patients, 
Table 2 Characteristics of patients with septic shock in the entire study cohort and propensity-matched sample

\begin{tabular}{|c|c|c|c|c|}
\hline & $\begin{array}{l}\text { Overall } \\
n=563 \\
n(\%)\end{array}$ & $\begin{array}{l}\text { Treated } \\
\text { matched } \\
n=108 \\
n(\%)\end{array}$ & $\begin{array}{l}\text { Untreated } \\
\text { matched } \\
n=108 \\
n(\%)\end{array}$ & $P^{a}$ \\
\hline \multicolumn{5}{|l|}{ Patient characteristics } \\
\hline Age in yrs, mean, $\mathrm{SD}^{\mathrm{c}}$ & $67.1(15.5)$ & $62.9(17.2)$ & $64.2(16.1)$ & 0.53 \\
\hline Male ${ }^{c}$ & $284(50.4)$ & $60(55.6)$ & $57(52.8)$ & 0.64 \\
\hline Body mass index, mean, SD ${ }^{c}$ & $28.0(8.6)$ & $27.3(7.8)$ & $27.8(7.5)$ & 0.66 \\
\hline APACHE II, mean, SD ${ }^{c}$ & $24.8(8.3)$ & $24.5(8.4)$ & $23.9(8.3)$ & 0.54 \\
\hline \multicolumn{5}{|l|}{ Comorbidities } \\
\hline Congestive heart failure $^{c}$ & $86(15.3)$ & $10(9.2)$ & $15(13.9)$ & 0.28 \\
\hline Diabetes $^{c}$ & $172(30.5)$ & $25(23.2)$ & $20(18.5)$ & 0.40 \\
\hline Hypertension $^{c}$ & $320(56.9)$ & $51(47.2)$ & $53(49.1)$ & 0.76 \\
\hline Chronic pulmonary disease $^{c}$ & $266(47.3)$ & $42(38.9)$ & $40(37.0)$ & 0.77 \\
\hline Neurologic disease ${ }^{c}$ & $8(1.4)$ & $1(0.9)$ & $0(0)$ & 1.00 \\
\hline Chronic kidney disease $^{c}$ & $132(23.5)$ & $22(20.4)$ & $24(22.2)$ & 0.73 \\
\hline Cancer $^{c}$ & $121(21.5)$ & $7(6.5)$ & $7(6.5)$ & 1.00 \\
\hline Chronic liver disease $^{c}$ & $36(6.4)$ & $10(9.3)$ & $8(7.4)$ & 0.62 \\
\hline Chronic pancreatitis $^{c}$ & $3(0.5)$ & $1(0.9)$ & $1(0.9)$ & 1.00 \\
\hline \multicolumn{5}{|l|}{ Organ failure } \\
\hline Kidney ${ }^{c}$ & $161(28.6)$ & $33(30.6)$ & $34(31.5)$ & 0.88 \\
\hline Respiratory $^{c}$ & $296(52.6)$ & $61(56.5)$ & $61(56.5)$ & 1.00 \\
\hline Hematologic $^{c}$ & $214(38.0)$ & $52(48.1)$ & $49(45.4)$ & 0.67 \\
\hline Metabolic/lactic acidosis ${ }^{c}$ & $262(46.5)$ & $60(55.6)$ & $60(55.6)$ & 1.00 \\
\hline \multicolumn{5}{|l|}{ Number of organ failures } \\
\hline 1 & $104(18.5)$ & $13(12.0)$ & $12(11.1)$ & \\
\hline 2 & $169(30.0)$ & $30(27.8)$ & $32(29.6)$ & \\
\hline 3 & $147(26.1)$ & $30(27.8)$ & $32(29.6)$ & $0.97^{b}$ \\
\hline 4 & $102(18.1)$ & $24(22.2)$ & $20(18.5)$ & \\
\hline 5 & $41(7.3)$ & $11(10.2)$ & $12(11.1)$ & \\
\hline Inotrope ${ }^{c}$ & $123(21.9)$ & $30(27.8)$ & $32(29.6)$ & 0.77 \\
\hline Steroid $^{c}$ & $219(38.9)$ & $50(46.3)$ & $46(42.6)$ & 0.59 \\
\hline Insulin drip ${ }^{c}$ & $153(27.2)$ & $37(34.3)$ & $32(29.7)$ & 0.46 \\
\hline Statins $^{c}$ & $65(11.6)$ & $19(17.6)$ & $16(14.8)$ & 0.59 \\
\hline Chemical DVT prophylaxis $^{c}$ & $319(56.7)$ & $76(70.4)$ & $74(68.5)$ & 0.77 \\
\hline \multicolumn{5}{|l|}{ Sepsis source } \\
\hline Abdomen & $86(15.3)$ & $12(11.1)$ & $20(18.5)$ & \\
\hline Blood & $34(6.0)$ & $9(8.3)$ & $3(2.8)$ & \\
\hline Lung & $251(44.6)$ & $54(50.0)$ & $42(38.9)$ & $0.08^{b}$ \\
\hline Urinary Tract & $101(17.9)$ & $20(18.5)$ & $22(20.4)$ & \\
\hline Other/unknown & $91(16.2)$ & $13(12.0)$ & $21(19.4)$ & \\
\hline
\end{tabular}

\footnotetext{
${ }^{a}$ The $P$-value for treated matched vs. untreated matched adjusted for matching by propensity.

${ }^{b} P$-values, one for the number of organ failures, and one for sepsis source, because each test is being done as a chi-square test on a $2 \times 5$ crosstable.

${ }^{c}$ The 22 variables used in the propensity matching.

Abbreviations: APACHE, Acute Physiology and Chronic Health Evaluation; DVT, deep vein thrombosis; $P, P$-value; SD, standard deviation; yrs, years.
} 
because there was no indication of a positive effect. The 28 -day rate of death from any cause was $18.5 \%$ in the rhAPC group and $17 \%$ in the placebo group $(P=0.34)$. The in-hospital mortality rate was $20.6 \%$ in the rhAPC group and $20.5 \%$ in the placebo group $(P=0.98)$. Serious bleeding occurred in $2.4 \%$ of patients receiving rhAPC and in $1.2 \%$ of patients receiving the placebo $(P=0.02)$ during the drug-infusion period. No significant difference was observed in the rate of intracranial hemorrhage $(0.3 \%$ with rhAPC and $0.2 \%$ with the placebo) [10].

The efficacy of rhAPC in severe sepsis remains a matter of dispute. Some experts even criticized the Food and Drug Administration's decision to approve rhAPC [24-26]. The main criticisms were aimed at intercurrent changes made in the PROWESS protocol, among them the exclusion of participants who were thought to be likely to die within 28 days because of the severity of the underlying disease and the introduction of new cell lines for growing the rhAPC protein. The use of a subgroup analysis of data from a major trial to identify suitable candidates for treatment was also heavily criticized. Mackenzie, Carlet and others suggested that a general recommendation for the clinical use of rhAPC was premature or not justified $[27,28]$. On the other hand, Surviving Sepsis Guidelines suggested the use of rhAPC for severe septic patients who have multiorgan failure or a high risk of death [21]. As a result, two large multicenter, randomized, double-blind trials investigating the use of rhAPC in septic shock are currently underway $[17,18]$.

The patients in our trial had mortality rates higher than those observed in the PROWESS trial, possibly because we only studied septic shock patients that might be sicker than the patient population in PROWESS. In our study, we had fewer patients with single organ failure, a similar number of patients with two or three organ failures, but more patients with four or five organ failures than PROWESS. In our study, the more organ failures, the higher was the mortality in both groups. Across all organ failure subgroups (one, two, three, four, or five organ failure subgroups), in-hospital mortality was persistently higher in the group that did not receive rhAPC than the group that received rhAPC (data not shown). The higher relative risk reduction in mortality in our study (33.9\% vs $13 \%$ in PROWESS) is likely due to the fact that rhAPC is most beneficial in the sickest septic shock patients, with multiple organ failures. The bleeding rate in our study was smaller than that observed in PROWESS, but similar to that observed in other major clinical trials [23].

In our study, there was no difference between the matched treated and matched untreated groups in days on vasopressors, days on mechanical ventilation, length of ICU stay in days, and length of hospital stay in days (Table 3). These findings are not surprising and are similar to those found in PROWESS [9]. This adds to the evidence that survivors of treated versus untreated groups look fairly similar, but more patients survived in the treated group. This also suggests that rhAPC improves hospital survival without the consumption of additional resources.

Our study is limited in that it is a retrospective analysis and that the number of patients is relatively small. However, this propensity analysis provides an estimate of the benefit of rhAPC in a natural hospital setting.

Table 3 Outcomes of patients with septic shock in the entire study cohort and propensity-matched sample

\begin{tabular}{|c|c|c|c|c|}
\hline & $\begin{array}{l}\text { Overall, } \\
n=563 \\
\mathrm{n}(\%)\end{array}$ & $\begin{array}{l}\text { Treated matched, } \\
n=108 \\
\mathrm{n}(\%)\end{array}$ & $\begin{array}{l}\text { Untreated matched, } \\
n=108 \\
\mathrm{n}(\%)\end{array}$ & $P^{a}$ \\
\hline \multicolumn{5}{|l|}{ Main outcomes } \\
\hline Length of stay, median days, (IQR) ${ }^{\mathrm{b}}$ & $22(12,39)$ & $19.5(11,33)$ & $27(12,45)$ & 0.11 \\
\hline Hospital mortality & $266(47.2)$ & $38(35.2)$ & $57(53.8)$ & 0.005 \\
\hline \multicolumn{5}{|l|}{ Intensive care unit outcomes } \\
\hline Mortality & $226(40.1)$ & $36(33.3)$ & $47(43.5)$ & 0.09 \\
\hline Length of stay, median days, (IQR) & $9.3(4.0,21.3)$ & $11(6,22)$ & $11.3(4.5,28)$ & 0.90 \\
\hline Days on ventilator, median, (IQR) & $8.8(3.7,22.6)$ & $9(6,22)$ & $8.7(4.3,24)$ & 0.80 \\
\hline Days on vasopressors, median, (IQR) & $2(1,3)$ & $2(1,4)$ & $2(1,3)$ & 0.90 \\
\hline \multicolumn{5}{|l|}{ Complications } \\
\hline Gastrointestinal bleeding & $9(1.6)$ & $3(2.8)$ & $0(0.0)$ & 1.00 \\
\hline Intracranial bleeding & $1(0.2)$ & $0(0)$ & $0(0)$ & 1.00 \\
\hline Minor transfusion & $216(38.4)$ & $38(35.2)$ & $45(41.7)$ & 0.27 \\
\hline Major transfusion & $45(8.5)$ & $4(3.7)$ & $10(9.3)$ & 0.09 \\
\hline Any transfusion(minor and/or major) & $243(43.2)$ & $41(38.0)$ & $50(46.3)$ & 0.16 \\
\hline
\end{tabular}

${ }^{a}$ The $P$-value for treated matched vs. untreated matched adjusted for matching by propensity.

${ }^{b} \mathrm{IQR}$, interquartile range. 
That makes it different from an estimate made from a randomized controlled trial (RCT), where conditions are more controlled. An RCT tells us that there is a causal effect of a certain size. A propensity analysis of retrospective data tells us what size effect we can expect under normal hospital conditions. Also, fewer patients (110) received rhAPC than those who did not (453). This could be explained by the possibility that treatment was preferentially directed toward patients thought to have a higher likelihood of meaningful survival, a lower risk of bleeding, or contraindication to rhAPC by the managing intensivist. However, it is not explained by differences in the types of patients receiving it versus not since we used all possible recorded pre-treatment variables. In addition, the 108 untreated patients are also candidates for rhAPC therapy in the sense that they have propensities to receive rhAPC that match the propensities of those 108 patients actually receiving rhAPC. There was also no evidence of a difference in any of the bleeding variables between the two groups (Table 3). Usage of rhAPC also depended upon whether the intensivist caring for the patient was critical or supportive of rhAPC. However, usage of rhAPC has remained constant over the study period, seen graphically and by non-significant hypothesis tests (t-test, Wilcoxon test and logistic regression all have $P$-values near 0.5$)$. Our primary outcome measure was in-hospital mortality; we did not have access to longerterm outcomes, and, thus, our survival analyses assumed patients who were discharged alive from the hospital were in fact alive at Day 28. However, this study is made stronger by the propensity-matched analysis. Our primary outcome was in-hospital mortality, and rhAPC began to show its effect in the ICU (Table 3). ICU mortality comes close to statistical significance with $P=0.09$; however, if we make the test one-sided in the hypothesized direction, the $P$-value becomes 0.045 . In-hospital mortality shows fuller statistical significance (which of course includes ICU mortality). A recent similar study conducted by Lindenauer et al. showed similar results [29]. In a propensity-matched sample in which all covariates achieved balance, receipt of rhAPC was associated with reduced hospital mortality $(40.7 \%$ vs. $46.6 \%$; risk ratio, $0.87 ; 95 \%$ confidence interval, 0.80 to 0.95 ). Four rhAPC-treated patients $(0.25 \%)$ had hemorrhagic stroke, 107 (6.8\%) had gastrointestinal bleeding, and five (0.3\%) required major transfusion [29]. An important limitation of the study by Lindenauer et al. is that all the data on their patients were based on billing records, and not direct clinical measurements.

\section{Conclusions}

Patients with septic shock who were treated with rhAPC had a reduced in-hospital mortality compared with patients with septic shock with similar acuity who were not treated with rhAPC. In addition, time on mechanical ventilation, time on vasopressors, length of ICU stay and bleeding complications did not differ between the groups. Pending results from large multicenter studies evaluating rhAPC in septic shock patients, our analysis adds to the evidence that early initiation of rhAPC may improve survival of patients with septic shock who are at low risk of bleeding.

\section{Key messages}

- The efficacy of recombinant human activated protein $C$ (rhAPC) in sepsis remains a matter of dispute.

- Pending results from two large multicenter, randomized, double-blind trials, we examined the association between treatment with rhAPC and outcomes among patients with septic shock in routine clinical practice in a large university-affiliated Intensive Care Unit.

- We performed a propensity-matched analysis, which equalizes the probability of receiving rhAPC, mimicking a randomized comparison.

- Patients with septic shock who were treated with rhAPC had reduced in-hospital mortality compared with patients with septic shock with similar acuity who were not treated with rhAPC, with no difference in complications.

- Our analysis provides an estimate of the benefit of rhAPC in septic shock patients in a natural hospital setting.

\section{Abbreviations}

ADDRESS: The Administration of Drotrecogin Alfa (Activated) in Early Stage Severe Sepsis; APACHE II: Acute Physiology And Chronic Health Evaluation II; ICU: Intensive Care Unit; NNT: number needed to treat; PI: Project IMPACT; PROWESS: Prospective Recombinant Human Activated Protein C Worldwide Evaluation in Severe Sepsis; RCT: randomized controlled trial; rhAPC: recombinant human activated protein C; SOFA: sequential organ failure assessment.

\section{Acknowledgements}

The authors would also like to acknowledge Margaret Cytron, R.N., Kimberly Fowler, R.N. and Mary Lesko, R.N., B.S.N for their assistance in data collection for this manuscript. We would also like to acknowledge Edward Spitznagel, PhD for his statistical support.

\section{Authors' contributions}

FS contributed to conceiving the study, acquiring and managing the data, analyzing the data and interpreting the results, drafting and revising the manuscript, and approving the manuscript in its final form. JO, MM, JS and AV contributed to acquiring and managing the data, revising the

manuscript, and approving the manuscript in its final form. RT contributed to analyzing the data and interpreting the results, revising the manuscript, and approving the manuscript in its final form.

\section{Competing interests}

The authors declare that they have no competing interests.

Received: 15 December 2010 Revised: 2 February 2011

Accepted: 8 March 2011 Published: 8 March 2011 


\section{References}

1. Martin GS, Mannino DM, Eaton S, Moss M: The epidemiology of sepsis in the United States from 1979 through 2000. N Engl J Med 2003, 348:1546-1554

2. Brun-Buisson C, Doyon F, Carlet J, Dellamonica P, Gouin F, Lepoutre A, Mercier JC, Offenstadt G, Régnier B: Incidence, risk factors, and outcome of severe sepsis and septic shock in adults: a multicenter prospective study in intensive care units. JAMA 1995, 274:968-974.

3. Karlsson S, Ruokonen E, Varpula T, Ala-Kokko TI, Pettilä V, Finnsepsis Study Group: Long-term outcome and quality-adjusted life years after severe sepsis. Crit Care Med 2009, 37:1268-1274.

4. Angus DC, Linde-Zwirble WT, Lidicker J, Clermont G, Carcillo J, Pinsky MR: Epidemiology of severe sepsis in the United States: analysis of incidence, outcome, and associated costs of care. Crit Care Med 2001, 29:1303-1310.

5. Chalfin DB, Holbein ME, Fein AM, Carlon GC: Cost-effectiveness of monoclonal antibodies to gram-negative endotoxin in the treatment of gram-negative sepsis in ICU patients. JAMA 1993, 269:249-254.

6. Wheeler AP, Bernard GR: Treating patients with severe sepsis. N Engl J Med 1999, 340:207-214.

7. Parrillo JE, Parker MM, Natanson C, Suffredini AF, Danner RL, Cunnion RE, Ognibene FP: Septic shock in humans: advances in the understanding of pathogenesis, cardiovascular dysfunction, and therapy. Ann Intern Med 1990, 113:227-242.

8. Bernard GR, Vincent JL, Laterre PF, LaRosa SP, Dhainaut JF, LopezRodriguez A, Steingrub JS, Garber GE, Helterbrand JD, Ely EW, Fisher CJ Jr, Recombinant human protein C Worldwide Evaluation in Severe Sepsis (PROWESS) study group: Efficacy and safety of recombinant human activated protein C for severe sepsis. N Engl J Med 2001, 344:699-709.

9. Laterre PF, Levy H, Clermont G, Ball DE, Garg R, Nelson DR, Dhainaut JF, Angus DC: Hospital mortality and resource use in subgroups of the Recombinant Human Activated Protein C Worldwide Evaluation in Severe Sepsis (PROWESS) trial. Crit Care Med 2004, 32:2207-2218.

10. Abraham E, Laterre PF, Garg R, Levy H, Talwar D, Trzaskoma BL, François B, Guy JS, Brückmann M, Rea-Neto A, Rossaint R, Perrotin D, Sablotzki A, Arkins N, Utterback BG, Macias WL, Administration of Drotrecogin Alfa (Activated) in Early Stage Severe Sepsis (ADDRESS) Study Group: Drotrecogin alfa (activated) for adults with severe sepsis and a low risk of death. N Engl J Med 2005, 353:1332-1341.

11. Bernard GR, Margolis BD, Shanies HM, Ely EW, Wheeler AP, Levy H, Wong K, Wright TJ, Extended Evaluation of Recombinant Human Activated Protein C United States Investigators: Extended evaluation of recombinant human activated protein C United States Trial (ENHANCE US): A single-arm, phase $3 B$, multicenter study of drotrecogin alfa (activated) in severe sepsis. Chest 2004, 125:2206-2216.

12. Vincent $J L$, Bernard GR, Beale R, Doig C, Putensen C, Dhainaut JF, Artigas A, Fumagalli $R$, Macias W, Wright $T$, Wong $K$, Sundin DP, Turlo MA, Janes J: Drotrecogin alfa (activated) treatment in severe sepsis from the global open-label trial ENHANCE: Further evidence for survival and safety and implications for early treatment. Crit Care Med 2005, 33:2266-2277.

13. Hoyert DL, Arias E, Smith BL, Murphy SL, Kochanek KD: Deaths: final data for 1999. Natl Vital Stat Rep 2001, 49:1-113.

14. Neilson AR, Burchardi H, Chinn C, Clouth J, Schneider H, Angus D: Cost effectiveness of drotrecogin alfa (activated) for the treatment of severe sepsis in Germany. J Crit Care 2003, 18:217-227.

15. Angus DC, Linde-Zwirble WT, Clermont G: Cost-effectiveness of drotrecogin alfa (activated) in the treatment of severe sepsis. Crit Care Med 2003, 31:1-11

16. Davies A, Ridley S, Hutton J, Chinn C, Barber B, Angus DC: Cost effectiveness of drotrecogin alfa (activated) for the treatment of severe sepsis in the United Kingdom. Anaesthesia 2005, 60:155-162.

17. Finfer $S$, Ranieri VM, Thompson BT, Barie PS, Dhainaut JF, Douglas IS, Gårdlund B, Marshall JC, Rhodes A: Design, conduct, analysis and reporting of a multi-national placebo-controlled trial of activated protein C for persistent septic shock. Intensive Care Med 2008, 34:1935-1947.

18. University of Versailles. Activated protein $C$ and corticosteroids for human septic shock (APROCCHS). [http://clinicaltrials.gov/ct2/show/ NCT00625209]

19. Bone RC, Balk RA, Cerra FB, Dellinger RP, Fein AM, Knaus WA, Schein RM, Sibbald WJ: Definitions for sepsis and organ failure and guidelines for the use of innovative therapies in sepsis. The ACCP/SCCM Consensus
Conference Committee. American College of Chest Physicians/Society of Critical Care Medicine. Chest 1992, 101:1644-1655.

20. Dellinger RP, Carlet JM, Masur H, Gerlach H, Calandra T, Cohen J, GeaBanacloche J, Keh D, Marshall JC, Parker MM, Ramsay G, Zimmerman JL, Vincent JL, Levy MM, Surviving Sepsis Campaign Management Guidelines Committee: Surviving Sepsis Campaign guidelines for management of severe sepsis and septic shock. Crit Care Med 2004, 32:858-873.

21. Dellinger RP, Levy MM, Carlet JM, Bion J, Parker MM, Jaeschke R, Reinhart K, Angus DC, Brun-Buisson C, Beale R, Calandra T, Dhainaut JF, Gerlach H, Harvey M, Marini JJ, Marshall J, Ranieri M, Ramsay G, Sevransky J, Thompson BT, Townsend S, Vender JS, Zimmerman JL, Vincent JL, International Surviving Sepsis Campaign Guidelines Committee; American Association of Critical-Care Nurses; American College of Chest Physicians; American College of Emergency Physicians; Canadian Critical Care Society; European Society of Clinical Microbiology and Infectious Diseases; European Society of Intensive Care Medicine, et al: Surviving Sepsis Campaign: International guidelines for management of severe sepsis and septic shock: 2008. Crit Care Med 2008, 36:296-327.

22. Rosenbaum PR, Ross RN, Silber JH: Minimum distance matched sampling with fine balance in an observational study of treatment for ovarian cancer. JASA 2007, 102:75-83.

23. Laterre PF: Clinical trials in severe sepsis with drotrecogin alfa (activated). Crit Care 2007, 11:S5.

24. Fumagalli $R$, Mignini MA: The risk profile of drotrecogin alfa (activated). Crit Care 2007, 11:S6.

25. Warren HS, Suffredini AF, Eichacker PQ, Munford RS: Risks and benefits of activated protein C treatment for severe sepsis. N Engl J Med 2002, 347:1027-1030

26. Poole D, Bertolini G, Garattini S: Errors in the approval process and postmarketing evaluation of drotrecogin alfa (activated) for the treatment of severe sepsis. Lancet Infect Dis 2009, 9:67-72.

27. Mackenzie AF: Activated protein C: do more survive? Intensive Care Med 2005, 31:1624-1626.

28. Carlet J: Prescribing indications based on successful clinical trials in sepsis: a difficult exercise. Crit Care Med 2006, 34:525-529.

29. Lindenauer PK, Rothberg MB, Nathanson BH, Pekow PS, Steingrub JS: Activated protein $C$ and hospital mortality in septic shock: a propensitymatched analysis. Crit Care Med 2010, 38:1101-1107.

doi:10.1186/cc10089

Cite this article as: Sadaka et al: Activated protein C in septic shock: a propensity-matched analysis. Critical Care 2011 15:R89.

\section{Submit your next manuscript to BioMed Central and take full advantage of:}

- Convenient online submission

- Thorough peer review

- No space constraints or color figure charges

- Immediate publication on acceptance

- Inclusion in PubMed, CAS, Scopus and Google Scholar

- Research which is freely available for redistribution

Submit your manuscript at www.biomedcentral.com/submit
C Biomed Central 